\title{
Study on Molecular Interaction of Aqueous Ascorbic Acid (Vitamin C) at 293k
}

\author{
V. G. Dudhe ${ }^{1, *}$, V.A. Tabhane ${ }^{2}$, O.P. Chimankar ${ }^{3}$, C.M. Dudhe ${ }^{4}$ \\ ${ }^{1}$ Shri Shivaji College, Rajura, Dist:-Chandrapur-442905 \\ ${ }^{2}$ Department of Physics, University of Pune, Pune \\ ${ }^{3}$ Department of Physics, R.T.M Nagpur University, Nagpur - 440001 \\ ${ }^{4}$ Department of Physics, Institutes of Science, Nagpur -440001 \\ *Corresponding Author: vishalgdudhe@gmail.com
}

Copyright (C) 2014 Horizon Research Publishing All rights reserved.

\begin{abstract}
The ultrasonic wave propagation through liquid solution has been used to give the important information about the behavior of molecular interaction of liquid molecules. The density, viscosity and ultrasonic velocity of aqueous Ascorbic acid have been studied at temperature 293K. From the experimental data various parameters such as acoustic impedance, adiabatic compressibility, free length, free volume, Wada's constant and Rao's constant have been calculated. The molecular interactions in aqueous Ascorbic acid in term of this parameter have been discussed.
\end{abstract}

Keywords Ultrasonic Velocity, Adiabatic Compressibility, Free length, Molecular Interaction

\section{Introduction}

Vitamins are organic compounds that are needed to cell and organs for maintaining their functions and developments. They take role in enzymes processes either co-enzymes or their precursors and in genetic regulation processes. They may also act as antioxidants. Most of the vitamin cannot be synthesized by the body, thus it must be taken through diets. Vitamins are classified as water soluble and fat soluble vitamin. Ascorbic acid is a water soluble vitamin [1].

Ascorbic acid is plays an important role to development of brain of unborn baby. Deficiency of ascorbic acid can have significant effect on the baby's brain development, which cannot be corrected with after birth vitamin C supplementation. Vitamin $\mathrm{C}$ also plays multiple roles in the health of adults. It is required to form collagen, protein found in the skin, connective tissue and blood vessels. It is also boosts immunity and helps to repair tissue damage [2].

The study of ultrasonic has large number of applications in basic science, agricultures, medicals, engineering's, and industries. The ultrasonic velocity, density, viscosity and it's thermo-acoustical parameters play an important role to studies the molecular interaction of liquid [3-11]

This paper gives the study on molecular interaction of ascorbic acid by using ultrasonic velocity, density, viscosity and others thermo-acoustical parameters at temperature 293K.

\section{Materials and Methods}

The stock solution of vitamin ascorbic acid was prepared in double distilled water. Solutions of different concentration were prepared using water as solvent. The ultrasonic velocity of pure solvent and their solutions measurement were carried out with a highly versatile and accurate 'pulse echo overlap technique (PEO) method by using automatic ultrasonic recorder (AUAR-102) and frequency counter. The frequency of the pulses was kept at 5MHz. The density and viscosity were measured using hydrostatic plunger method and Oswald's viscometer respective.

Temperature $293 \mathrm{~K}$ is maintained using Thermo-statically controlled water circulation system with accuracy of $0.5^{\circ} \mathrm{C}$. The other thermo-acoustical parameters such as acoustic impedance, adiabatic compressibility, free length, free volume, Wada's constant and Rao's constant are evaluate using ultrasonic velocity, density and viscosity. The experimental data of concentration (M), ultrasonic velocity $(u)$, viscosity ( $\mathrm{y})$, density ( $\rho)$, acoustic impedance (z), adiabatic compressibility $(\beta)$, free length $\left(L_{f}\right)$, free volume $\left(\mathrm{V}_{\mathrm{f}}\right)$, Wada's constant $(\mathrm{W})$ and Rao's constantan $(\mathrm{R})$ for different concentration of ascorbic acid are given in the table 1 and 2 
Table 1. Wada's constant (W) and Rao's constantan (R) for different concentration of ascorbic acid

\begin{tabular}{|c|c|c|c|c|c|}
\hline Conc. & $\underset{\mathbf{m ~ s}^{-1}}{\mathbf{u}}$ & $\begin{array}{c}\rho \\
\mathrm{Kg} \mathrm{m}^{-3}\end{array}$ & $\begin{array}{l}\eta \mathbf{x} 10^{-3} \\
\mathbf{N s} / \mathbf{m}^{2}\end{array}$ & $\begin{array}{c}\text { B x10 } \\
\mathbf{m}^{2} \mathbf{N}^{-10}\end{array}$ & $\begin{array}{c}\mathrm{Zx10}^{6} \\
\mathrm{Kg} \mathrm{m}^{-2} \mathrm{~s}^{-1}\end{array}$ \\
\hline 0 & 1482.68 & 998.2 & 1.01 & 4.5571 & 1.4800 \\
\hline 0.02 & 1484.05 & 1000.67 & 1.0275 & 4.5374 & 1.4850 \\
\hline 0.04 & 1484.71 & 1003.43 & 1.0336 & 4.5209 & 1.48981 \\
\hline 0.06 & 1486.32 & 1004.19 & 1.0346 & 4.5077 & 1.49255 \\
\hline 0.08 & 1487.90 & 1006.69 & 1.0404 & 4.4869 & 1.49785 \\
\hline 0.10 & 1489.16 & 1008.21 & 1.0525 & 4.4726 & 1.50139 \\
\hline
\end{tabular}

Table 2. Wada's constant (W) and Rao's constantan (R) for different concentration of ascorbic acid

\begin{tabular}{|c|c|c|c|c|}
\hline Conc. & $\mathbf{L}_{\mathbf{f}} \mathbf{x} \mathbf{1 0}^{-\mathbf{1 1}} \mathbf{( \mathbf { m } )}$ & $\begin{array}{c}\mathbf{V}_{\mathbf{f}} \mathbf{x} \mathbf{1 0}^{-\mathbf{4}} \\
\mathbf{m}^{\mathbf{3}} / \mathbf{m o l e}\end{array}$ & $\begin{array}{c}\mathbf{W} \\
\left.\left(\mathbf{m}^{\mathbf{3}} / \mathbf{m o l e}\right) \mathbf{( \mathbf { N }} / \mathbf{m}^{\mathbf{2}}\right)^{\mathbf{1 / 7}}\end{array}$ & $\mathbf{R}\left(\mathbf{m}^{\mathbf{3}} / \mathbf{m o l}\right)(\mathbf{m} / \mathbf{s})^{\mathbf{1 / 3}}$ \\
\hline 0 & 4.1619 & 4.8510 & 0.3895 & 0.2056 \\
\hline 0.02 & 4.1529 & 4.7568 & 0.3900 & 0.2058 \\
\hline 0.04 & 4.1453 & 4.7399 & 0.3904 & 0.2059 \\
\hline 0.06 & 4.1393 & 4.7630 & 0.3919 & 0.2065 \\
\hline 0.08 & 4.1297 & 4.7538 & 0.3920 & 0.2067 \\
\hline 0.10 & 4.1231 & 4.6999 & 0.3928 & 0.2071 \\
\hline
\end{tabular}

\section{Theory}

Ultrasonic velocity was measured by using pulse Echo overlap method at $5 \mathrm{MHz}$. The interferometer was filled with test liquid and temperature was maintained by circulating water around the measuring cell from thermostat. From the experimental data of ultrasonic velocity, density and viscosity of given solution, various thermo-acoustical parameters were calculated using following standard equation.

1] Ultrasonic velocity: $\quad \mathrm{u}=\frac{2 d}{t}$

Where, $\mathrm{d}=$ Separation between transducer $\&$ reflector $\mathrm{t}=$ Traveling time period of ultrasonic wave.

2] Density: $\rho=\left[\frac{\mathrm{W}_{\mathrm{a}}-\mathrm{W}_{1}}{\mathrm{~W}_{\mathrm{a}}-\mathrm{W}_{\mathrm{w}}}\right] \mathrm{x} \rho_{\mathrm{w}}$

Where, $\mathrm{W}_{\mathrm{a}}=$ Weight of the plunger in air

$\mathrm{W}_{1}=$ Weight of the plunger in the experimental liquid

$\mathrm{W}_{\mathrm{w}}=$ Weight of the plunger in water

$\rho_{\mathrm{w}}=$ Density of water

3] Viscosity $\eta=\left[\frac{\rho \mathrm{xt}_{1}}{\rho_{\mathrm{w}} \mathrm{xt}_{\mathrm{w}}}\right] \times \eta_{w}$

Where, $\mathrm{t}_{1}=$ Flow Time in experimental liquid $\mathrm{t}_{\mathrm{w}}=$ Flow Time in water $\eta_{\mathrm{w}}=$ Viscosity of water

4] Adiabatic Compressibility $\beta=\left[1 / u^{2} \rho\right]$

5] Acoustic impedance $Z=$ u. $\rho$

6] Intermolecular free length: $\left(\mathrm{L}_{\mathrm{f}}\right)=\frac{k}{u \rho^{1 / 2}}$

Where, $k=$ Time dependent constant

7] Free volume: $\left(V_{f}\right)=M_{w} u / k \eta$

Where, $\mathrm{k}=$ Time independent constant

8] Wada's Constant : $(\mathrm{W})=\left(\mathrm{M}_{\mathrm{w}} / \rho\right) \times \beta^{-1 / 7}$

Where, $\mathrm{M}_{\mathrm{w}}=$ Molecular weight of experimental solution

9] Rao's Constant : $(R)=\left(M_{w} / \rho\right) \times u^{1 / 3}$

\section{Results and Discussion}

The experimental data of density, viscosity, and ultrasonic velocity, adiabatic compressibility and acoustic impedance of ascorbic acid at $293 \mathrm{~K}$, are recorded in table 1 , and Intermolecular free length, free volume, Wada's constant and Rao's constant are given in table 2 .

The linear variation in ultrasonic velocity and adiabatic compressibility with concentration of ascorbic acid in water is indicate that, there is a significant interaction between the solute-solvent components of the aqueous ascorbic acid [12-14]which shown in figure (1) and figure (4).

Variation of density with concentration is shown in figure (2), which indicates that, the density of aqueous ascorbic acid is increases with the concentration. 


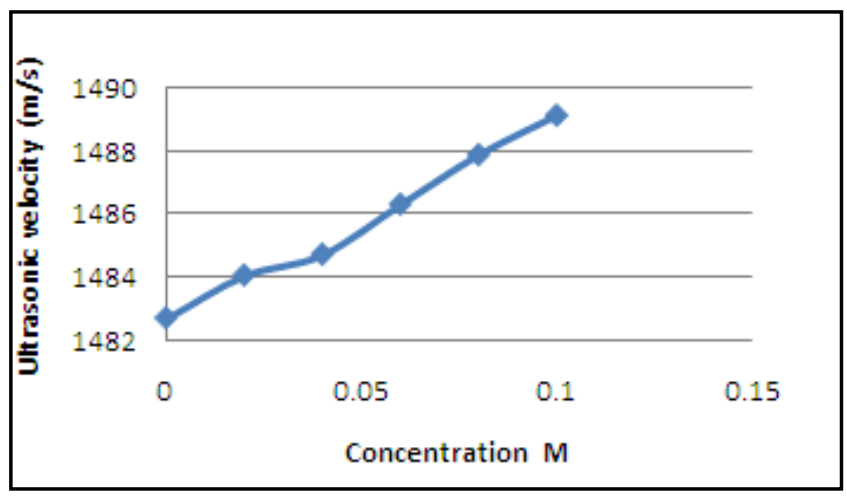

Figure 1. Variation of Ultrasonic velocity with Concentration

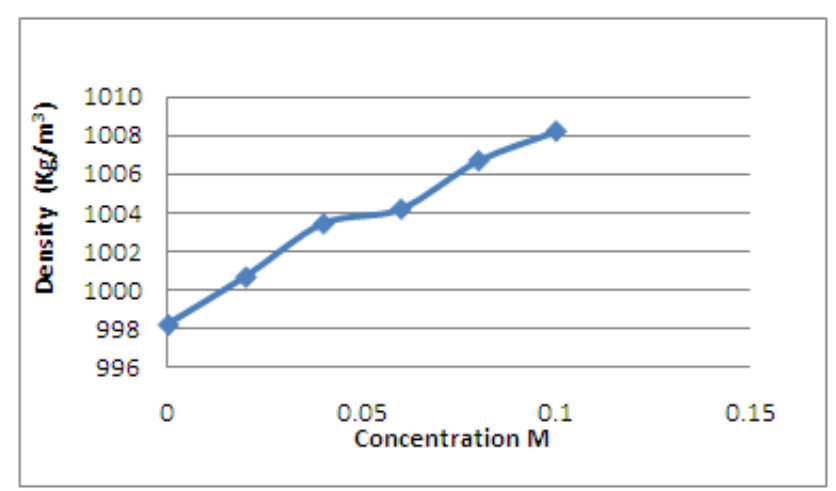

Figure 2. Variation of Density with Concentration

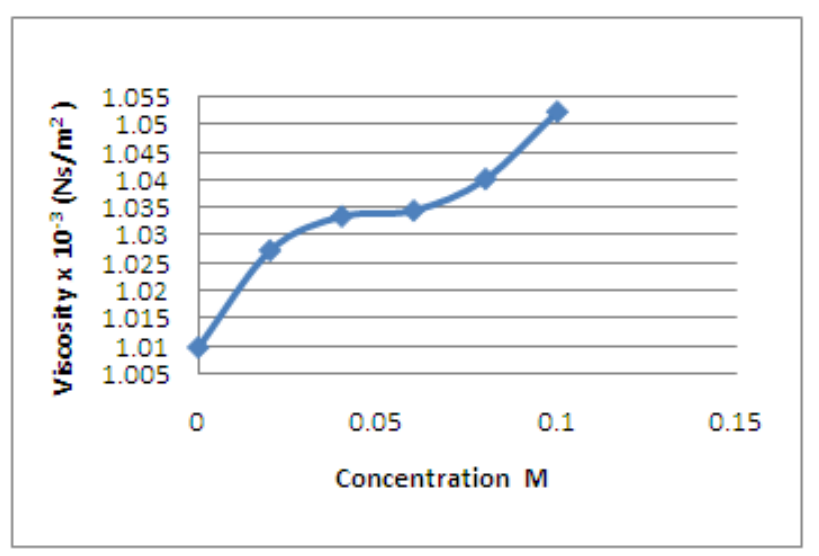

Figure 3. Variation of Viscosity with Concentration

In figure (3) gives the viscosity of aqueous ascorbic acid increases linearly with the concentration, which indicating increases fractional resistance force that may be due to change in (i) effective molecular area or (ii) the cohesive/adhesive forces or (iii) relative random velocity between the components of the mixture or combination of these [15].

The molecule of liquid are not closely packed, there is always some space between them, this free space is known as free volume. The variation of free volume with concentration shown in figure (7) which shows that solute-solvent molecules are coming close to each other and space between them is decreases with rise in concentration. This supports to the strong solute-solvent interaction in liquid solution [16].

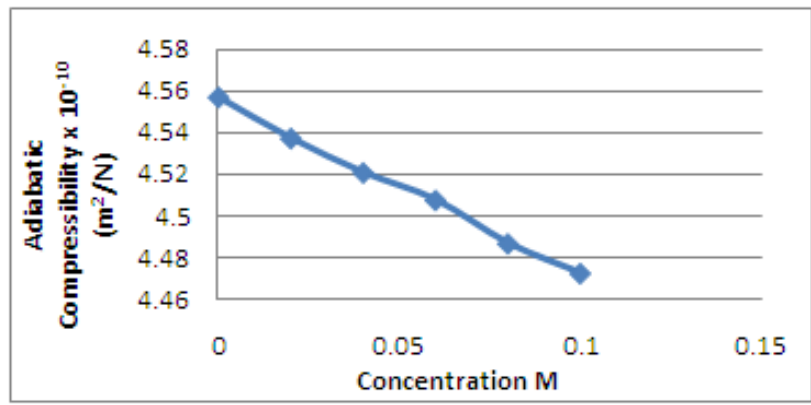

Figure 4. Variation of Adiabatic compressibility with Concentration

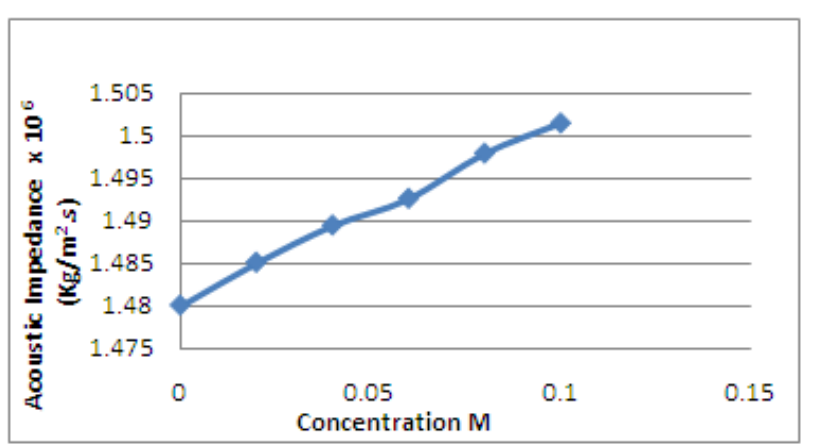

Figure 5. Variation of Acoustic Impedance with Concentration

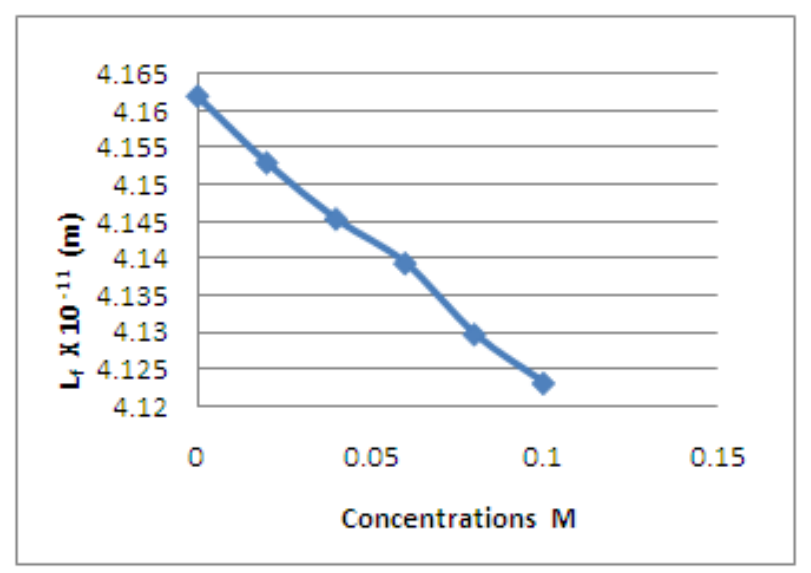

Figure 6. Variation of Free length with Concentration

The decrease in free length in figure (6) shows that, there is enhanced molecular association in these systems are increasing in ascorbic acid content, which show that compactness of the structure is increasing and it is less compressible [17]. However the acoustical impedance in figure (5) is increasing with the concentration of ascorbic acid. This in turn shows that molecular interaction is associative [18].

The variation of Wada's constant with concentration is shown in figure (8) to study the existence of molecular interaction Wada's constant is also very important. It is observed that Wada's constant increases with increasing concentration this indicate that solute-solvent molecular are 
very close and hence interaction is increasing. The variation of Rao's constant with concentration is show in figure (9). It is observed that Rao's constant increases with rise in concentration which supports the facts shown by other thermo-acoustical parameters.

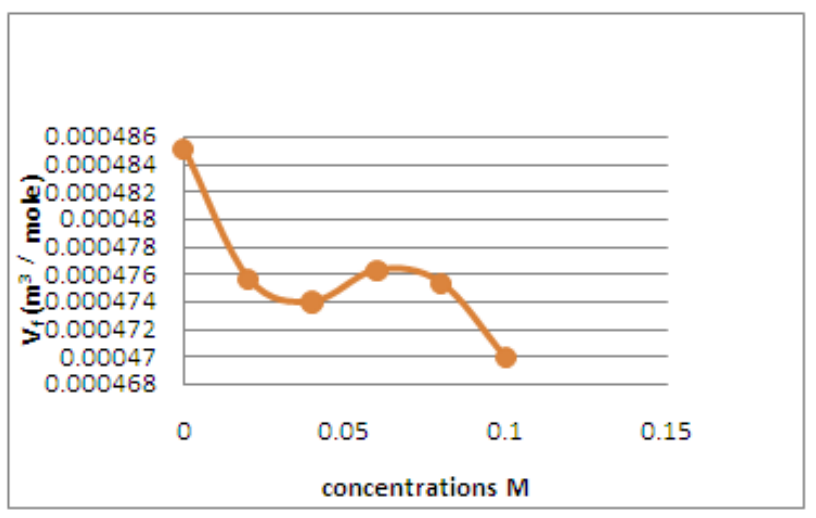

Figure 7. Variation of Free volume with Concentration

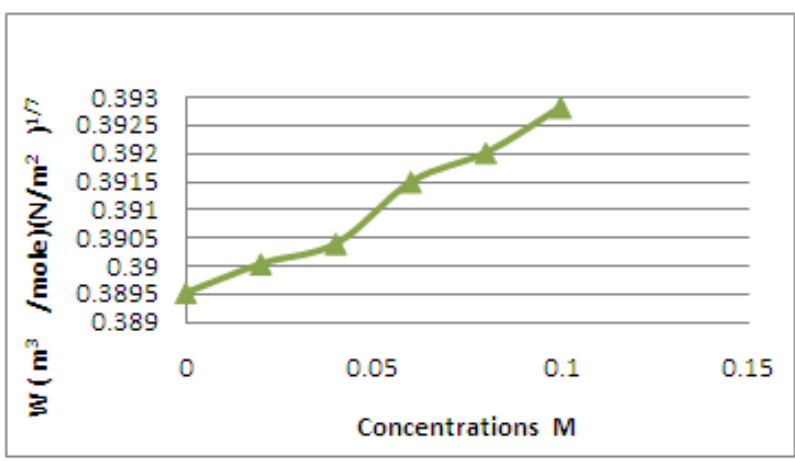

Figure 8. Variation of Wada's constant with Concentration

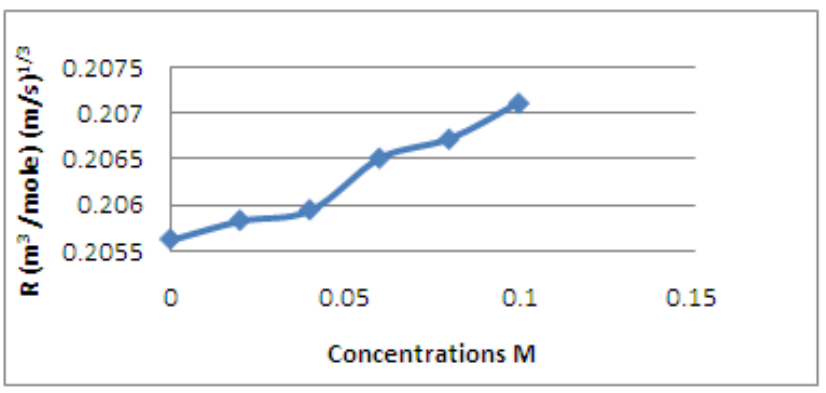

Figure 9. Variation of Rao's constant with Concentration

\section{Conclusions}

Ultrasonic velocity, density and viscosity are measured for aqueous solution of ascorbic acid of different concentration at $293 \mathrm{~K}$ and thermo-acoustical parameters are calculated. Velocity, viscosity, acoustical impedance, Wada's constant and Rao's constant are increases with concentration shows that solute-solvent interactions are present in the solution. The free volume, free length and adiabatic compressibility decreases with rise in concentration. This shows that strong solute-solvent interaction in a system are take place.

\section{REFERENCES}

[1] G. Anyranci, et al, J. Chem. Themodyn, Doi : 10, 1016/j jet 2007.04. 009, 2007

[2] Raw Michelle, Natural News.com,Nov.30, 2012

[3] P. V. Tabhane, O. P. Chimankar, C. M. Dudhe, V. A. Tabhane, Der Chemic Sinic 3(4) 944-947,2012

[4] P. V. Tabhane, O. P. Chimankar, C. M. Dudhe, V. A. Tabhane, Lop Conf. series material sci Engg.42 012033, doi: 10.1088/1757- 899A/42/012033, 2012

[5] O. P. Chimankar, Ranjita Shrivas, V. A. Tabhane, Archives of Applied science research 2(6):285-289,2010

[6] O. P. Chimankar, Ranjita Shrivas, S. Chopade,V. A. Tabhane, J. Chem.Pharm. Res,3(3) :579-586, 2011

[7] V. D. Bhandkar, O. P. Chimankar, A. A. mistry Pelagia Research Library, Advance in Applied Research, 2(63), 70-76, 2011

[8] G. Akgul, E. Bayram, E.Ayranci, J. Solution Chem. $35,1655-1972,2006$

[9] S. Annuradha, S. Prema, K. Rajgopal, J. Pure., Appl. Ultrasonic 27, 49-54, 2005

[10] M. K. Ravat, Sangeeta, Indian Journal of pure and Applied physics, 46, 187-192, 2008

[11] A. Ali, A. K. Nian, Acoustic let. 19-53, 1996

[12] Arti Gupta, Roli Strivastava, Archna Pandey, Global Adraneed Research J.Chem and mat. sci vol 1(3) PP 039-054, 2012

[13] A. N.Sonar, N. S. Pawar, Rasayan, J. Chem Vol 3 (1) $, 38-43,2010$

[14] V. D.Bhandakar, O. P. Chimankar, N.R. Pawar, J.chem. pharm. Res., 2(4), 873, 2010

[15] G.Arul, L.Palaniappan, Indian Journal of pure \& applied physics vol. 43, PP 755-758, 2005

[16] C. M.Dudhe , K.C. Patil, Int.J.of Natural Product research, 2(4) 76-78, 2012

[17] A.N.Sonar, N.S. Pawar, Rasayan J. Chem. Vol 3 no. $1,38-43,2010$

[18] V.A.Tabhane, Sangita Agrawal, and K.G. Rewatkar, J.Acous.soc. India vol. 28 no.1-4, 369-372, 2000 